\title{
(6) OPEN ACCESS \\ Repeated head trauma is associated with smaller thalamic volumes and slower processing speed: the Professional Fighters' Brain Health Study
}

\author{
Charles Bernick, ${ }^{1}$ Sarah J Banks, ${ }^{1}$ Wanyong Shin, ${ }^{2}$ Nancy Obuchowski, ${ }^{3}$ Sam Butler, ${ }^{3}$ \\ Michael Noback, ${ }^{1}$ Michael Phillips, ${ }^{2}$ Mark Lowe, ${ }^{2}$ Stephen Jones, ${ }^{2}$ Michael Modic ${ }^{2}$
}

\begin{abstract}
1 Lou Ruvo Center for Brain Health, Cleveland Clinic, Las Vegas, Nevada, USA ${ }^{2}$ Department of Radiology, Cleveland Clinic, Cleveland, Ohio, USA

${ }^{3}$ Department of Qualitative Health Sciences, Cleveland Clinic, Cleveland, Ohio, USA
\end{abstract}

\section{Correspondence to}

Dr Sarah J Banks, Lou Ruvo Center for Brain Health, Cleveland Clinic, 888 W Bonneville Ave, Las Vegas, Nevada 89106, USA; bankss2@ccf.org

Accepted 8 December 2014 Published Online First 29 January 2015
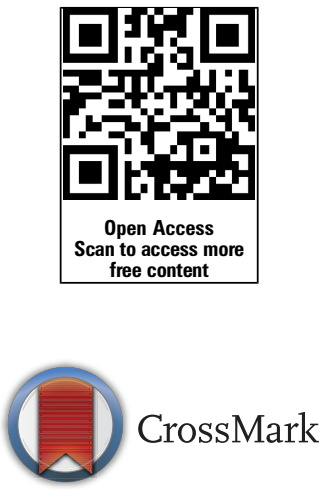

To cite: Bernick $C$ Banks SJ, Shin W, et al. Br J Sports Med 2015;49 1007-1011.

\begin{abstract}
Objectives Cumulative head trauma may alter brain structure and function. We explored the relationship between exposure variables, cognition and MRI brain structural measures in a cohort of professional combatants.
\end{abstract}

Methods 224 fighters (131 mixed martial arts fighters and 93 boxers) participating in the Professional Fighters Brain Health Study, a longitudinal cohort study of licensed professional combatants, were recruited, as were 22 controls. Each participant underwent computerised cognitive testing and volumetric brain MRI. Fighting history including years of fighting and fights per year was obtained from self-report and published records.

Statistical analyses of the baseline evaluations were applied cross-sectionally to determine the relationship between fight exposure variables and volumes of the hippocampus, amygdala, thalamus, caudate, putamen. Moreover, the relationship between exposure and brain volumes with cognitive function was assessed.

Results Increasing exposure to repetitive head trauma measured by number of professional fights, years of fighting, or a Fight Exposure Score (FES) was associated with lower brain volumes, particularly the thalamus and caudate. In addition, speed of processing decreased with decreased thalamic volumes and with increasing fight exposure. Higher scores on a FES used to reflect exposure to repetitive head trauma were associated with greater likelihood of having cognitive impairment.

Conclusions Greater exposure to repetitive head trauma is associated with lower brain volumes and lower processing speed in active professional fighters.

\section{INTRODUCTION}

Repetitive head trauma may be a risk factor for Alzheimer's disease and is considered the primary cause of chronic traumatic encephalopathy (CTE), ${ }^{1-5}$ a pathologically characterised neurodegenerative condition with diverse presentations during life. ${ }^{6}$ The potential long-term effects of cumulative head trauma on the brain have come to public view with the recognition that athletes in contact sports including American football demonstrated postmortem findings associated with CTE; a few of these reported cases harbouring very focal lesions have occurred in individuals under 20 years of age.

A fundamental question that needs more exploration is the relationship between the amount, or dose, of head trauma and alteration in brain structure and function. Previous studies in boxers have reported frequency and duration of fighting to be associated with cognitive or neurological problems. ${ }^{7} 8$ Moreover, postmortem studies of CTE have revealed changes in a number of subcortical and cortical regions (9-11). With advances in neuroimaging, segmentation of these structures can be completed with automated programmes which are widely available, reproducible, and thus, if these regions prove to be markers of decline with repetitive traumatic brain injury, they have the potential to become clinically useful and readily calculated biomarkers.

The Professional Fighters Brain Health Study (PFBHS) is a longitudinal cohort study of boxers and mixed martial arts (MMA) fighters designed to better understand the effects of repeated blows to the head on brain structure and function over time. This cross-sectional analysis of participants' baseline evaluation explores the relationship between exposure to repeated blows to the head and MRI measures of brain structure and function, along with cognitive performance.

\section{METHODS}

Participants in the PFBHS are athletes, age 18 and older, who have at least a fourth grade reading level and are licensed to fight professionally in one of the combat sports, boxing or MMA. In addition, we recruited a control group who were matched on age and education to the fighter group. The control participants had no reported history of head trauma in civilian or military life, nor could they have played a sport associated with head injuries (eg, football, rugby, hockey, boxing, MMA, wrestling, soccer, rodeo) at a high school level or beyond. Participants are seen for baseline evaluation and on an annual basis thereafter over the next 4 years. Methods of recruitment and study procedures have been described previously. ${ }^{9}$ Data for this study come from the baseline evaluations.

At the baseline visit, participants answer questionnaires with the assistance of the study coordinator that collect information on demographics; educational attainment; previous head trauma, both related and unrelated to athletic activities; and prior involvement in other contacts sports. Before the study visit, the fighter's professional record was obtained from commonly cited websites (boxrec. com for boxers and mixed martial arts.com and sherdog.com for MMA fighters) to determine number of years of professional fighting, number and outcome of professional fights, and frequency of professional fighting.

Cognitive function was assessed by a computerbased battery that consists of four subtests of the 
CNS Vital Signs (CNS Vital Signs, North Carolina) including verbal memory, symbol digit coding, Stroop and a finger tapping test. CNS Vital Signs offers robust and reliable measurements of cognition which are computerised but are supervised by a technician. Raw summary scores were used for all analyses. Results from these tests are used to make up scores in various clinical domains: verbal memory, processing speed, psychomotor speed and reaction time. ${ }^{10}$

A high resolution T1-weighted anatomical MRI was obtained on all fighters. Scans were performed using the same Siemens $3 \mathrm{~T}$ Verio scanner with a 32 channel head coil (Siemens Medical Systems, Erlangen, Germany). Acquisition protocol details were $\mathrm{TR} / \mathrm{TE} / \mathrm{TI}=2300 / 2.98 / 900$, flip angle $=9, \quad \mathrm{BW}=240 \mathrm{~Hz} / \mathrm{Px}$, $240 \times 256$ matrix, 160 slices, voxel size $=1 \times 1 \times 1.2 \mathrm{~mm}$, scan time: 9:14. Volumes of the hippocampus and amygdala and subcortical grey matter including thalamus, caudate and putamen were calculated using the automated full brain segmentation process in Freesurfer software. ${ }^{11}$ The volumes of each structure were measured in both hemispheres separately.

\section{Statistical analysis}

The primary goal of the current study was to test for an association between fight exposure and brain volumes. Repeated measures analysis of variance was performed to test the association between the outcome variables and fight exposure variables. Five pairs of dependent variables, left and right thalamus, left and right hippocampus, left and right caudate, left and right putamen, and left and right amygdala were evaluated in separate models. Fight exposure was characterised by the total number of professional fights and the number of years of professional fighting. In univariate analyses the associations of these two continuous variables with brain volume were assessed using linear and quadratic effects, as well as cubic splines. A Fight Exposure Score (FES) had previously been derived as a function of cumulative fights and intensity of exposure (ie, total number of professional fights and number of professional fights per year; see table 1) and was also evaluated in this study. The FES detailed here has been explained in previous publications. ${ }^{9}$ Scores on the FES ranged from 0 to 4 with 4 representing the greatest exposure. Though there was only one subject with a score of 3 , this category was maintained to ensure symmetry with scores of 1 and 2. In each model we included the type of fighter (boxer or MMA); we tested the significance of the interaction term for the type of fighter with the other exposure variable. All analyses were adjusted for intracranial volume (ICV; treated as a continuous variable), age (treated as a continuous variable), education (defined as no college level vs some college level) and race (defined as: (1) Caucasian, (2) African-American and (3) other

Table 1 Fight Exposure Score

\begin{tabular}{|c|c|c|c|c|}
\hline $\begin{array}{l}\text { Fight } \\
\text { Exposure } \\
\text { Score }\end{array}$ & $\begin{array}{l}\text { Number } \\
\text { of pro } \\
\text { fights }\end{array}$ & $\begin{array}{l}\text { Mean } \\
\text { number } \\
\text { of pro } \\
\text { fights/ } \\
\text { year }\end{array}$ & $\begin{array}{l}\text { Boxer age mean } \\
\text { (minimum, } \\
\text { maximum, n) }\end{array}$ & $\begin{array}{l}\text { MMA age mean } \\
\text { (minimum, } \\
\text { maximum, n) }\end{array}$ \\
\hline 0 & 0 & 0 & $24.8(19,35,28)$ & $26.6(19,40,21)$ \\
\hline 1 & $1-15$ & $\leq 1$ & $28.2(19,39,12)$ & $28.8(21,40,18)$ \\
\hline 2 & $1-15$ & $>1$ & $26.5(18,40,29)$ & $27.6(19,39,55)$ \\
\hline 3 & $>15$ & $\leq 1$ & $44(44,44,1)$ & - \\
\hline 4 & $>15$ & $>1$ & $31.8(24,43,23)$ & $30.1(2238,36)$ \\
\hline
\end{tabular}

(Asian, Pacific Islander, American Indian and Alaskan Native)). A significance level of 0.05 was used to test the effect of the exposure variables on brain volumes.

Models were also constructed to assess differences between the fighter groups and controls in brain volume. A comparison of estimated reduction in brain volume between boxers, MMA and control while controlling for age, years of education, race and number of professional fights was completed to assess the specificity of our findings to fighters. Dunnett's test was used for contrasting mean responses against controls and making adjustments for multiple comparisons within a particular measure.

Secondary goals of the study were to test for associations between brain volume and cognitive test scores and between fight exposure and cognitive test scores. Generalised linear models were constructed with cognitive scores as the dependent variables and brain volume or fight exposure variables as the independent variables of interest; analyses were adjusted for ICV, age, race and education. Cognitive scores were compared against age-matched and education level-matched normative values (based on cutpoints at $1.5 \times \mathrm{SD}$ below the mean) provided to our group by CNS Vital Signs to define presence/absence of impairment. Associations between types of impairment and the FES were evaluated using $\chi^{2}$ tests. All analyses were performed in SAS V.9.2.

\section{RESULTS}

Complete data were collected on 224 male fighters: 93 boxers and 131 MMAs, and 22 controls. The fighters' age ranged from 18 to 44 with median of 27 years. There were 89 (39.7\%) Caucasians, 59 (26.3\%) African-Americans and 76 (33.9\%) others. Fifty-four per cent of the participants had less than or equal to a high school education; $46 \%$ had at least some college-level education.

The total number of years of professional fighting ranged from 0 to 24 , with a mean of 4 years. The total number of professional fights ranged from 0 to 101, with a mean of 10 fights. Table 2 summarises the amateur and professional years of fighting, number of fights and knock-outs by the type of fighting.

A summary table of the results of various measures of exposure and brain volumes is given in table 3. Type of fighting was correlated with thalamic and hippocampal volumes with boxers having lower volumes than MMA fighters. In general, increasing exposure either as measured by the number of professional fights or years of professional fighting is associated with lower brain structure volumes, particularly with subcortical structures.

Table 2 Fight exposure by type of fighting*

\begin{tabular}{lcc}
\hline & Boxers $(\mathrm{n}=93)$ & MMA $(\mathrm{n}=131)$ \\
\hline $\begin{array}{l}\text { Years of fighting } \\
\text { Amateur }\end{array}$ & $3.8(0-23)$ & $1.8(0-22)$ \\
$\quad$ Professional & $4.0(0-25)$ & $4.3(0-16)$ \\
Number of fights & & \\
$\quad$ Amateur & $38.1(0-242)$ & $14.6(0-397)$ \\
$\quad$ Professional & $10.5(0-101)$ & $11.8(0-81)$ \\
Knock-outs suffered & & \\
$\quad$ Amateur & $0.05(0-2)$ & $0.06(0-2)$ \\
$\quad$ Professional & $0.9(0-13)$ & $0.6(0-6)$ \\
Age (years) & $27.7(18-44)$ & $28.2(19-40)$ \\
\hline *Mean (low value-high value). &
\end{tabular}


Table 3 Summary of correlations between exposure measures and brain volumes

\begin{tabular}{|c|c|c|c|c|c|}
\hline & Thalamus & Hippocampus & Caudate & Putamen & Amygdala \\
\hline $\begin{array}{l}\text { Estimated reduction in volume for } \\
\text { boxers relative to MMA fighters }\end{array}$ & $\begin{array}{l}3.3 \% \\
p=0.006\end{array}$ & $\begin{array}{l}2.0 \%(L) \text { and } 4.2 \%(R)^{*} \\
p=0.007\end{array}$ & $\mathrm{p}=0.349$ (NS) & $\begin{array}{l}2.3 \% \\
p=0.089 \text { (NS) }\end{array}$ & $\begin{array}{l}2.9 \% \\
p=0.051 \text { (NS) }\end{array}$ \\
\hline $\begin{array}{l}\text { Estimated reduction in volume } \\
\text { per professional fight }\end{array}$ & $\begin{array}{l}0.3 \%(\mathrm{~L}) \text { and } 0.4 \%(\mathrm{R}) \text { for boxers*; } \\
0.2 \%(\mathrm{~L}) \text { and } 0.3 \%(\mathrm{R}) \text { for } \mathrm{MMA}^{*} \\
\mathrm{p}=0.001^{*} \dagger\end{array}$ & $\begin{array}{l}0.1 \%(\mathrm{~L}) \text { and } 0.2 \%(\mathrm{R}) \text { for boxers*; } \\
0.1 \% \text { for } \mathrm{MMA} \\
\mathrm{p}=0.080+(\mathrm{NS})\end{array}$ & $\begin{array}{l}0.3 \% \\
p=0.008\end{array}$ & $\mathrm{p}=0.516$ (NS) & $\begin{array}{l}0.2 \% \\
p=0.076 \text { (NS) }\end{array}$ \\
\hline $\begin{array}{l}\text { Estimated reduction in volume per } \\
\text { year of professional fighting }\end{array}$ & $\begin{array}{l}0.5 \% \text { for boxers only } \\
p=0.050+\text { (NS) }\end{array}$ & $\mathrm{p}=0.828$ (NS) & $\begin{array}{l}0.4 \% \\
p=0.023\end{array}$ & $\mathrm{p}=0.750$ (NS) & $\mathrm{p}=0.259$ (NS) \\
\hline $\begin{array}{l}\text { Estimated reduction in volume for } \\
\text { each unit increase in Exposure Composite Index }\end{array}$ & $\begin{array}{l}0.8 \% \\
p=0.042\end{array}$ & $\mathrm{p}=0.415$ (NS) & $\begin{array}{l}0.8 \% \\
p=0.075 \text { (NS) }\end{array}$ & $p=0.665$ (NS) & $\begin{array}{l}0.9 \% \\
p=0.052 \text { (NS) }\end{array}$ \\
\hline
\end{tabular}

The most consistent relationship between exposure variables and brain volume was seen in the thalamus and caudate.

Utilising the FES, each increase in the score was associated with reductions of $0.8 \%, 0.9 \%$ and $0.8 \%$ in volumes of the caudate, amygdala and thalamus (see figure 1), respectively. There was no specific threshold of number of professional fights or FES where the relationship between number of professional fights or FES and brain volumes was seen.

When comparing brain volumes by type of fighter and controls, significant differences were seen between boxer and MMA fighters for all right and left brain measures and for several right and left brain measures for boxers and controls (table 4).

Among the various cognitive domains, only speed of processing was significantly related to volume and exposure. Smaller volumes of the thalamus, amygdala and left hippocampus were associated with lower scores on speed of processing measures (figure 2). Boxers had significantly lower scores than MMA fighters $(\mathrm{p}<0.001)$.

There was a significant relationship between the number of professional fights and speed of processing $(p=0.041)$, with an estimated $0.19 \%$ reduction in processing speed per fight. Similarly, there was a significant relationship between the FES and speed of processing $(p=0.023)$, with an estimated $2.1 \%$ reduction in processing speed scores for each increase in FES.

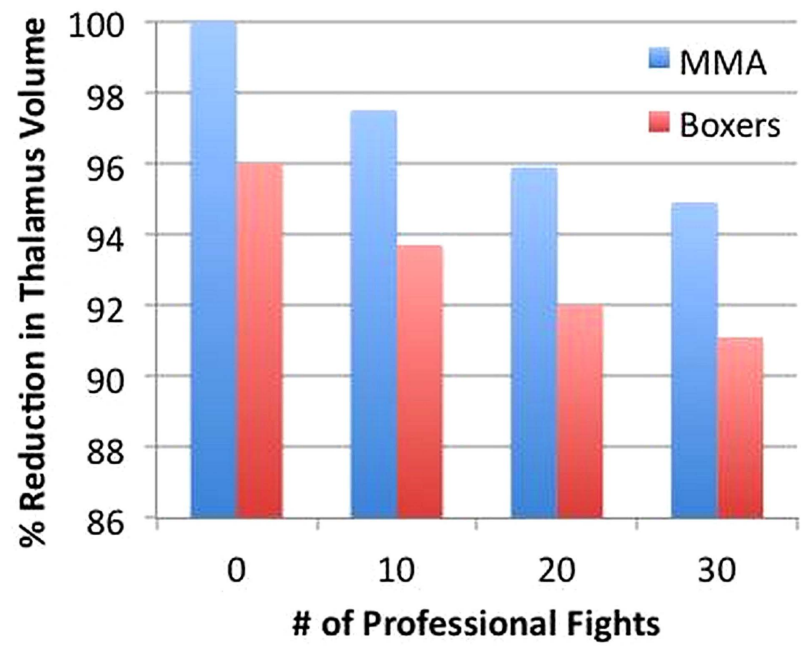

Figure 1 Illustration of association between thalamus volume and the number of professional fights for boxers and mixed martial arts (MMA) fighters. The estimated mean volumes are standardised relative to a MMA fighter with zero professional fights.
The effect was most evident at the extremes of the FES, where fighters with a score of 4 have an $8.8 \%$ age-adjusted, race-adjusted and education-adjusted reduction in scores relative to fighters with a FES of 0 . In models constructed to compare the three participant groups on the four cognitive measures (and including age, education and race in the model), no differences were seen for verbal memory. Processing speed was related to fighter type (adjusting for years of education) with both fighter groups scoring worse than controls, but boxers being overall slower than MMA fighters.

Figure 3 illustrates the proportion of participants impaired, defined as 1.5 SD below age-matched and education levelmatched normative values, for the various cognitive domains as a function of the participants' FES. The proportions of participants with verbal memory impairment and with psychomotor speed impairment increased significantly with the magnitude of the FES ( $p=0.036$ and $p=0.046$, respectively). Note that although we saw a significant association between the FES and speed of processing scores, this correlation was not seen when the analysis was limited to the proportion of those who were in an impaired range $(p=0.244)$.

\section{DISCUSSION}

\section{Summary of results}

From a cross-sectional analysis of professional fighters participating in the PFBHS, increasing exposure to recurrent head trauma measured in several different ways was associated with lower MRI-based volumes of various cortical and subcortical brain structures, particularly the thalamus and caudate. In addition, lower scores on tests of processing speed were correlated with lower brain volumes and increasing levels of exposure. Brain structure volumes were generally less for boxers than MMA fighters or controls, and there were differences in cognitive measures between both fighter types and controls which were independent of any relationship with age. Finally, higher scores on a FES used to reflect exposure to repetitive head trauma were associated with a greater likelihood of having measurable cognitive impairment.

This is the first report linking fight exposure to regional volumes using MRI measures. There are several potential implications of these findings. Not only does it appear that differences in MRI volumetrics associated with fight exposure can be detected in relatively young individuals, but these differences occur in particular subcortical structures. Moreover, the volumetric findings are correlated with at least some clinical measures. 
Table 4 Summary of difference in volume between fighter groups and controls on the various brain measures

\begin{tabular}{|c|c|c|c|c|c|}
\hline Hemisphere & $\begin{array}{l}\text { Thalamus } \\
\% \text { ( } p \text { value) }\end{array}$ & $\begin{array}{l}\text { Caudate } \\
\% \text { ( } p \text { value) }\end{array}$ & $\begin{array}{l}\text { Putamen } \\
\% \text { ( } p \text { value) }\end{array}$ & $\begin{array}{l}\text { Hippocampus } \\
\% \text { ( } p \text { value) }\end{array}$ & $\begin{array}{l}\text { Amygdala } \\
\% \text { (p value) }\end{array}$ \\
\hline \multicolumn{6}{|l|}{ Left side } \\
\hline Boxer vs MMA & $7(<0.0001)$ & $5.1(0.01)$ & $4.5(0.009)$ & $4.1(0.007)$ & $5.7(0.006)$ \\
\hline Boxer vs control & $6.8(0.045)$ & NS & $7.2(0.02)$ & NS & $8.6(0.02)$ \\
\hline MMA vs control & NS & NS & NS & NS & NS \\
\hline \multicolumn{6}{|l|}{ Right side } \\
\hline Boxer vs MMA & $7.0(<0.0001)$ & $6.3(0.001)$ & $4.8(0.003)$ & $4.7(<0.0001)$ & $6.4(0.0007)$ \\
\hline Boxer vs control & $6.6(0.02)$ & NS & $8.0(0.007)$ & $6.1(0.03)$ & NS \\
\hline MMA vs control & NS & NS & NS & NS & NS \\
\hline
\end{tabular}

\section{Subcortical structures and exposure}

The thalamus and caudate showed the strongest correlation with fight exposure. They have extensive connections with other cortical and subcortical structures. ${ }^{12} 13$ The thalamus acts as a 'gateway' to the cortex, and when affected can influence many neurological functions. There may be several mechanisms by which the thalamus and caudate are vulnerable to volumetric loss. Rotational movement of the head as induced by punches in boxing or MMA can result in diffuse axonal injury in white matter tracts ${ }^{14}$; it is possible that Wallerian degeneration can follow this white matter injury resulting in neuronal loss in subcortical grey matter structures. ${ }^{15}$ In addition, torsional forces could produce fluid waves in the lateral ventricles that conceivably may directly injure adjacent structures (ie, thalamus, caudate). ${ }^{16}$

\section{Differences between boxers and MMA fighters}

Though the relationship between greater fight exposure and lower subcortical volumes was seen in boxers and MMA fighters, the finding that boxers had lower brain volumes than the MMA fighters could be due to several factors. Perhaps the most obvious explanation is that boxers get hit in the head more. In addition to trying to concuss (ie, knock out) their opponent, MMA fighters can utilise other combat skills such as wrestling and jiu jitsu to win their match by submission without causing a concussion. ${ }^{17}$ In a review of 60 consecutive fights within the 125-145 pound weight class utilising reports from professional services that count number of punches in professional fights (compuboxonline.com, fightmetric.com), boxers received, on

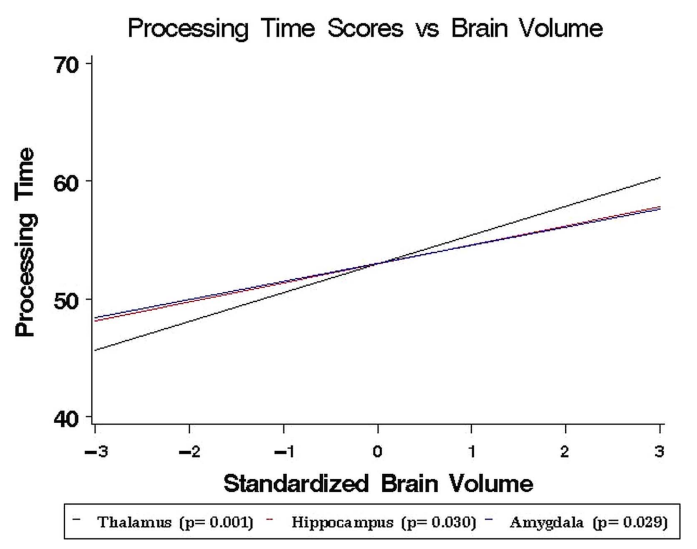

Figure 2 Association between brain volume (in one-unit SD increments below and above the mean) and processing speed scores. Scores decrease 2-3\% per one SD decrease in brain volume. average, 175 total punches per fight versus 58 for MMA fighters. However, other differences between the two combat disciplines could influence the volumetric findings.

\section{FES and cognition}

Among the cognitive measures obtained in this study, processing speed was correlated with reduced volume in several cortical and subcortical structures. Processing speed is very non-specific in that it can be caused by impacted by various forms and loci of brain pathology; its reduction is consistent with repeated concussion and is considered a component of the clinical manifestation of CTE. ${ }^{18} 19$ Interestingly, processing speed was lower with higher values of the FES but, unlike brain volumes, only when comparing the extremes of the FES scale. Perhaps the clinical expression of underlying pathology may not appear in a measurable way until a substantial amount of structural damage has occurred. ${ }^{20}$

\section{The FES as a potential indicator of vulnerability to poor brain} outcome

There is a recognised need for instruments or tools that can be used by regulatory agencies to identify individuals who may be at higher risk of having brain injury from cumulative head trauma and require closer safety surveillance. Though exposure to head trauma is likely the primary predictor of injury, one of the challenges in understanding the effects of repetitive head trauma on brain structure and function is measuring the 'dose'

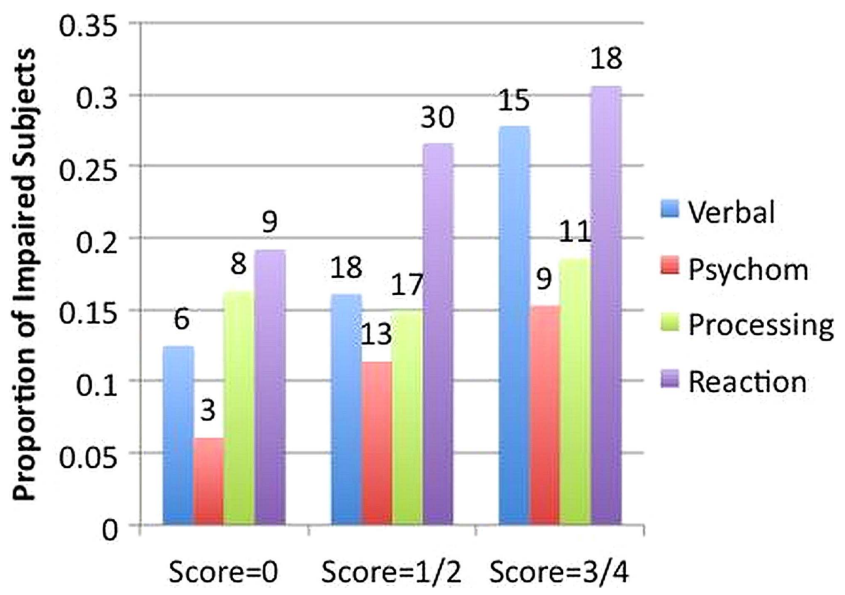

Figure 3 Illustration of the proportion of impaired fighters for the four cognitive domains as a function of the Fight Exposure Score (FES).

Values above bars indicate the number of impaired participants with the given FES. There were 49 participants with a FES of 0,114 participants with scores of 1 or 2 and 11 participants with scores of 3 or 4 . 
(amount and severity) of exposure. Several surrogate measures of head trauma that are verifiable include total number of professional fights and years of professional fights. Subconcussive injuries sustained during training may have an important indication for brain health. ${ }^{21} 22$ Number of fights may take into account the exposure rendered during training. Frequency of fighting (factoring in years of fighting) may be a complementary variable; fighting more frequently may reduce the time the brain has to fully recover from prior trauma and be a risk factor that interacts with number of fights. ${ }^{23} 24$

As a multidimensional measure of exposure, we utilised a FES based on number of professional fights and average fights per year, with scores ranging from 0 to 4 , higher scores representing greater exposure. Admittedly, the FES is limited to an estimate of actual fight exposure as we do not know details of exact number of blows or amounts of sparring that each fighter sustained.

Approximately 1 in 4 fighters with a FES of 3 or 4 scored in an impaired range on tests of verbal memory compared with only about 1 in 10 of those who had a FES of 0 . A similar effect was seen in tests of psychomotor speed, with participants in the FES $3 / 4$ group being three times more likely to be in an impaired range on psychomotor speed compared with a FES score of 0 . Pending review of its performance longitudinally and replication of our findings in a larger cohort of fighters, the FES (or some modification of it) may be an easy to use, practical tool that can select out fighters that may be more likely to have cognitive impairment or be going down that road.

\section{Limitations}

While the PFBHS is one of the largest reported cohorts of wellcharacterised active professional combatants, several limitations need to be acknowledged. The study group included in this report was not a random sample of fighters; participants were self-selected and may be less skilled or more susceptible to be knocked out. However, when we compared our participants with all those who fought in Nevada over the same year, participants in the PFBHS only differed by being younger and having slightly less professional fights, without a difference in winning percentage or times knocked out. Measures of exposure to head trauma are indirect and may not truly reflect the actual degree of head trauma each participant experienced. The cognitive testing was limited to a computerised battery that admittedly is not comprehensive. Furthermore, while the study coordinator would encourage the participants to provide their best effort during the testing period, the effort exerted by the participant may have been influenced by a variety of extraneous factors such as fatigue and dehydration. Because the participants may be sparring in close temporal relationship to the study visit, it is difficult to tease out acute from chronic effects of head trauma on cognitive performance. Finally, the relationship between exposure and brain volumes and cognition may have been due to some other factor related to exposure and not the exposure itself. While this large cross-sectional study cannot speak to causality, it provides extensive baseline data which will be used in future longitudinal studies of cognitive and neuroanatomical changes in this population to further understand the nature and of the correlational findings.

\section{Future implications}

Many investigators speculate that CTE is a neurodegenerative disease instigated by repeated head trauma that then continues to evolve even in the absence of further exposure. ${ }^{2}$ While this study is not specifically focused on CTE, the findings suggest that greater exposure to head trauma is related to detectable brain structural and performance deficits in active fighters. The answer to whether brain volumes and performance change over time with, and in the absence of further exposure will hopefully emerge as this cohort is followed longitudinally.

\section{What are the new findings?}

- Lower caudate and thalamus volumes were associated with more extensive fight history.

- Lower volumes of these structures related to lower processing speed.

- Our Fight Exposure Score which combines duration and intensity of fight career predicts the above relationships.

\section{How might it impact on clinical practice in the near future?}

- Suggests potential biomarkers of brain injury related to traumatic brain injury to be explored longitudinally.

- Work building on the present study may identify parameters by which to advise on utilisation of specific cognitive measures as part of regulatory requirements for professional fighting.

- The Fight Exposure Score may provide an important tool in establishing when in a career decisions regarding neurological checks or retirement from the sport are advisable.

Contributors $C B$ and $S B$ conceived of ideas and wrote the manuscript. WS, MM, $\mathrm{MP}, \mathrm{ML}$ and SJB were all involved in image processing and analysis, as well as manuscript review. NO and SB completed the statistics. MN was involved in analysis of fighter types and checked official fight records of all fighters.

\section{Competing interests None.}

Ethics approval Cleveland Clinic IRB.

Provenance and peer review Not commissioned; externally peer reviewed.

Open Access This is an Open Access article distributed in accordance with the Creative Commons Attribution Non Commercial (CC BY-NC 4.0) license, which permits others to distribute, remix, adapt, build upon this work non-commercially, and license their derivative works on different terms, provided the original work is properly cited and the use is non-commercial. See: http://creativecommons.org/ licenses/by-nc/4.0/

\section{REFERENCES}

1 Bazarian JJ, Cernak I, Noble-Haeusslein Linda, et al. Long-term neurologic outcomes after traumatic brain injury. J Head Trauma Rehabil 2009;24:439-51.

2 Gavett BE, Stern RA, McKee AC. Chronic traumatic encephalopathy: a potential late effect of sport-related concussive and subconcussive head trauma. Clin Sports Med 2011;30:179-88, xi.

3 Rabadi MH, Jordan BD. The cumulative effect of repetitive concussion in sports. Clin J Sport Med 2001;11:194-8.

4 Gardner A, Iverson GL, McCrory P. Chronic traumatic encephalopathy in sport: a systematic review. Br J Sports Med 2014;48:84-90.

5 Tator $\mathrm{CH}$. Chronic traumatic encephalopathy: how serious a sports problem is it? Br J Sports Med 2014;48:81-3.

6 Stern RA, Daneshvar DH, Baugh CM, et al. Clinical presentation of chronic traumatic encephalopathy. Neurology 2013;81:1122-9.

7 McCrory P, Zazryn T, Cameron P. The evidence for chronic traumatic encephalopathy in boxing. Sports Med 2007;37:467-76.

8 Heilbronner RL, Bush SS, Ravdin LD, et al. Neuropsychological consequences of boxing and recommendations to improve safety: a National Academy of Neuropsychology education paper. Arch Clin Neuropsychol 2009;24:11-19.

9 Bernick C, Banks S, Phillips M, et al. Professional Fighters Brain Health Study: rationale and methods. Am J Epidemiol 2013;178:280-6. 


\section{Original article}

10 Gualtieri CT, Johnson LG. Reliability and validity of a computerized neurocognitive test battery, CNS Vital Signs. Arch Clin Neuropsychol 2006;21:623-43.

11 Fischl B, Salat DH, Busa E, et al. Whole brain segmentation: automated labeling of neuroanatomical structures in the human brain. Neuron 2002;33: $341-55$.

12 Behrens TE, Johansen-Berg $\mathrm{H}$, Woolrich MW, et al. Non-invasive mapping of connections between human thalamus and cortex using diffusion imaging. Nat Neurosci 2003;6:750-7.

13 Yeterian EH, Van Hoesen GW. Cortico-striate projections in the rhesus monkey: the organization of certain cortico-caudate connections. Brain Res 1978; 139:43-63.

14 Blennow K, Hardy J, Zetterberg $\mathrm{H}$. The neuropathology and neurobiology of traumatic brain injury. Neuron 2012;76:886-99.

15 Minagar A, Barnett MH, Benedict RHB, et al. The thalamus and multiple sclerosis: modern views on pathologic, imaging, and clinical aspects. Neurology 2013;80:210-19.

16 Corsellis JA, Bruton CJ, Freeman-Browne D. The aftermath of boxing. Psychol Med 1973;3:270-303
17 Peterson CL, Ferrara MS, Mrazik M, et al. Evaluation of neuropsychological domain scores and postural stability following cerebral concussion in sports. Clin I Sport Med 2003;13:230-7.

18 Collins MW, Grindel SH, Lovell MR, et al. Relationship between concussion and neuropsychological performance in college football players. JAMA 1999;282:964-70.

19 Mendez MF. The neuropsychiatric aspects of boxing. Int I Psychiatry Med 1995;25:249-62.

20 Jack CR Jr, Knopman DS, Jagust WJ, et al. Hypothetical model of dynamic biomarkers of the Alzheimer's pathological cascade. Lancet Neurol 2010;9:119-28.

21 Stern RA, Riley DO, Daneshvar DH, et al. Long-term consequences of repetitive brain trauma: chronic traumatic encephalopathy. PM R 2011;3(10 Suppl 2): S460-7.

22 Jordan $B D$, Matser E, Zimmerman R, et al. Sparring and cognitive function in professional boxers. Phys Sportsmed 1996;24:87-98.

23 Forstl $\mathrm{H}$, Haass $\mathrm{C}$, Hemmer $\mathrm{B}$, et al. Boxing-acute complications and late sequelae: from concussion to dementia. Dtsch Arztebl Int 2010;107:835-9.

24 Cantu RC. Second-impact syndrome. Clin Sports Med 1998:17:37-44. 